\title{
EDITORIAL
}

\section{A first step against idiopathic pulmonary fibrosis}

\author{
B. Crestani
}

I diopathic pulmonary fibrosis (IPF) is a chronic devastating disease affecting 50 to 300 individuals per million with a median survival time of $\sim 3$ yrs [1]. The recent publication of evidence-based guidelines for the diagnosis and management of patients with IPF did not provide patients and care givers with any reason for optimism [2]. The only recommended procedures in this document were: long-term oxygen therapy in patients with clinically significant hypoxaemia; lung transplantation in selected patients; treatment of asymptomatic gastro-oesophageal reflux (although there is not even one randomised trial showing that this treatment improves lung function decline or survival in IPF patients); pulmonary rehabilitation; and corticosteroid use in patients with acute exacerbation of IPF [3]. Almost all treatment procedures evaluated in that statement were given either a weak or a strong recommendation against use [2].

However, the litany of the negative therapeutic trials in IPF ended with the recent publication of the results of three phase III trials evaluating the efficacy of pirfenidone [4-6]. The results of these trials, including $>1,000$ patients, support a protective effect of pirfenidone to limit the decline of lung function in patients with IPF [7]. This effect was the basis for

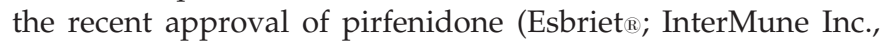
Brisbane, CA, USA) in the European Union (since February 28, 2011). Pirfenidone has been already available in Japan since 2008 (Pirespa®; Shionogi and Co. Ltd, Osaka, Japan) and a generic form was recently made available in India (Pirfenex $\mathbb{R}$; Cipla Ltd, Mumbai, India) [8]. Although a panel of experts voted for approval, the US Food and Drug Administration have not yet granted approval for pirfenidone and have requested that a further phase III clinical trial be performed. Pirfenidone is indicated in Europe in adults for the treatment of mild-to-moderate IPF [9]; however, there is already no consensus about what is mild IPF or moderate IPF compared to severe IPF [3]. A definition of these degrees of IPF severity is needed in order to provide all clinicians with the necessary common vocabulary. Unless we have this vocabulary, we should probably consider that pirfenidone use be limited to patients who meet the inclusion criteria of the CAPACITY (Clinical Studies Assessing Pirfenidone in IPF: Research of

Inserm, U700, Assistance Publique-Hôpitaux de Paris, Hôpital Bichat, Service de Pneumologie A, Centre de Compétence des Maladies Pulmonaires rares, and Faculté de Médecine, Université Paris Diderot, Paris, France.

CORRESPONDENCE: B. Crestani, Hôpital Bichat, Service de Pneumologie A, 46 rue Henri Huchard, 75877 Paris Cedex 18, France. E-mail: bruno.crestani@bch.aphp.fr

PROVENANCE: Submitted article, peer reviewed.
Efficacy and Safety Outcomes) trials, i.e. forced vital capacity $\geqslant 50 \%$ predicted and a diffusing capacity of the lung for carbon monoxide $\geqslant 35 \%$ pred [5].

The European approval signifies a new era for patients and doctors dealing with IPF in the European Union. First, it offers hope to patients and their families as this active antifibrotic molecule will be available very soon, and it gives doctors a weapon with which to combat this challenging disease. Secondly, it demonstrates that there is still room for nontargeted drugs in modern medicine. Indeed, although pirfenidone has been consistently shown to exert antifibrotic properties in animal models of renal, respiratory, cardiac or hepatic diseases [10-12], the exact mechanism of action of pirfenidone is still poorly understood and might, in fact, be multi-targeted as antioxidant, anti-transforming growth factor and anti-platelet derived growth factor properties have been demonstrated [12]. Further studies are needed to determine more precisely the antifibrotic pathways targeted by pirfenidone as this could help identify new antifibrotic molecules.

Thirdly, as soon as pirfenidone is made available to patients, the design of therapeutic trials in IPF patients will have to adapt to this new situation. Indeed, long-term, placebocontrolled studies will be ethically unsustainable in a progressive disease such as IPF. Both clinicians and pharmaceutical companies will have to incorporate this new information into the way therapeutic trials are developed in the future, at least in the countries where pirfenidone will be available.

Fourthly, IPF is only one of the fibrotic lung diseases that patients and clinicians face every day. For example, connective tissue diseases-associated lung fibrosis is very common and sometimes leads the prognosis, such as in patients with systemic sclerosis or rheumatoid arthritis [13]. Asbestosis and chronic hypersensitivity pneumonitis are environmentinduced lung fibrotic diseases with a poor prognosis and limited therapeutic possibilities [14, 15]. Idiopathic fibrotic nonspecific interstitial pneumonia is also a progressive fibrotic lung disease with a significant mortality, although it has a better prognosis than IPF [16]. Altogether, these fibrotic lung diseases have no approved treatment. The evaluation of a possible protective effect of pirfenidone is warranted before this drug is used in these patients. Indeed, we recently learnt that a protective effect in IPF does not necessarily translate into a protective effect in all fibrotic lung diseases, as illustrated by the negative trial of pirfenidone in Hermansky-Pudlak syndrome [17].

Finally, it is clear that pirfenidone is only the first step in the war against lung fibrosis. Pirfenidone has slowed the decline of 
lung function but it has not prevented acute exacerbations in the recent trials $[6,7]$. Furthermore, whether pirfenidone has the capacity to target the vascular remodelling which is responsible for the development of sometimes severe pulmonary hypertension in IPF patients is unknown [18]. Although this is a great time for patients with IPF, there is still room for antifibrotic drugs to come before the whole spectrum of fibrotic lung diseases gets covered.

\section{STATEMENT OF INTEREST}

B. Crestani received a fee for speaking from InterMune Inc.

\section{REFERENCES}

1 Raghu G, Weycker D, Edelsberg J, et al. Incidence and prevalence of idiopathic pulmonary fibrosis. Am J Respir Crit Care Med 2006; 174: 810-816.

2 Raghu G, Collard HR, Egan JJ, et al. An Official ATS/ERS/JRS/ ALAT Statement: Idiopathic Pulmonary Fibrosis: Evidence-based Guidelines for Diagnosis and Management. Am J Respir Crit Care Med 2011; 183: 788-824.

3 Raghu G. Idiopathic pulmonary fibrosis: guidelines for diagnosis and clinical management have advanced from consensus-based in 2000 to evidence-based in 2011. Eur Respir J 2011; 37: 743-746.

4 Taniguchi H, Ebina M, Kondoh Y, et al. Pirfenidone in idiopathic pulmonary fibrosis. Eur Respir J 2009; 35: 821-829.

5 Noble P, Albera C, Bradford W, et al. The CAPACITY (CAP) trials: randomized, double-blind, placebo-controlled, phase III trials of pirfenidone (PFD) in patients with idiopathic pulmonary fibrosis (IPF). Am J Respir Crit Care Med 2009; 179: A1129.

6 Noble P, Albera C, Bradford W, et al. The CAPACITY Program: two randomised, double-blind, placebo-controlled trials of pirfenidone in patients with idiopathic pulmonary fibrosis. Lancet 2011; [in press].
7 Spagnolo P, Del Giovane C, Luppi F, et al. Non-steroid agents for idiopathic pulmonary fibrosis. Cochrane Database Syst Rev 2010; 9: CD003134.

8 Pirfenidone tablets $200 \mathrm{mg}$. Pirfenex. www.cipla.com/whatsnew/ pirfenex.pdf Date last updated: October 2010.

9 European Medicines Agency. Public summary of opinion on orphan designation. EMA/COMP/198295/2004. March 23, 2011. www.ema.europa.eu/docs/en_GB/document_library/Orphan_ designation/2009/10/WC500006133.pdf

10 Kakugawa T, Mukae H, Hayashi T, et al. Pirfenidone attenuates expression of HSP47 in murine bleomycin-induced pulmonary fibrosis. Eur Respir J 2004; 24: 57-65.

11 Gurujeyalakshmi G, Hollinger MA, Giri SN. Pirfenidone inhibits PDGF isoforms in bleomycin hamster model of lung fibrosis at the translational level. Am J Physiol 1999; 276: L311-L318.

12 Macias-Barragan J, Sandoval-Rodriguez A, Navarro-Partida J, et al. The multifaceted role of pirfenidone and its novel targets. Fibrogenesis Tissue Repair 2010; 3: 16.

13 Antoniou KM, Margaritopoulos G, Economidou F, et al. Pivotal clinical dilemmas in collagen vascular diseases associated with interstitial lung involvement. Eur Respir J 2009; 33: 882-896.

14 Paris C, Thierry S, Brochard P, et al. Pleural plaques and asbestosis: dose- and time-response relationships based on HRCT data. Eur Respir J 2009; 34: 72-79.

15 Gaxiola M, Buendia-Roldan I, Mejia M, et al. Morphologic diversity of chronic pigeon breeder's disease: clinical features and survival. Respir Med 2011; 105: 608-614.

16 Travis WD, Hunninghake G, King TE Jr, et al. Idiopathic nonspecific interstitial pneumonia: report of an American Thoracic Society project. Am J Respir Crit Care Med 2008; 177: 1338-1347.

17 O'Brien K, Troendle J, Gochuico BR, et al. Pirfenidone for the treatment of Hermansky-Pudlak syndrome pulmonary fibrosis. Mol Genet Metab 2011; [Epub ahead of print DOI: 10.1016/j.ymgme.2011.02.003].

18 Ley B, Collard HR, King TE Jr. Clinical course and prediction of survival in idiopathic pulmonary fibrosis. Am J Respir Crit Care Med 2011; 183: 431-440. 